in vivo $33: 65-73$ (2019)

doi:10.21873/invivo.11440

\title{
Maslinic Acid Enhances Immune Responses in Leukemic Mice Through Macrophage Phagocytosis and Natural Killer Cell Activities In Vivo
}

\author{
KUANG-CHI LAI ${ }^{1,2}$, SHU-FEN PENG ${ }^{3}$, CHIA-CHI LIU ${ }^{4,5}$, JYE-YU HUANG ${ }^{6}$, JUNG-YU KUO ${ }^{6}$, ZHENG-YU \\ $\mathrm{CHENG}^{6}$, RICK SAI-CHUEN WU ${ }^{7,8}, \mathrm{CHIN}_{-\mathrm{CHUNG}} \mathrm{LIN}^{9,10}$, JR-KAI CHEN ${ }^{11^{*}}$ and JING-GUNG CHUNG ${ }^{6,12^{*}}$ \\ ${ }^{1}$ Department of Medical Laboratory Science and Biotechnology, College of Medicine and Life Science, \\ Chung Hwa University of Medical Technology, Tainan, Taiwan, R.O.C.; \\ ${ }^{2}$ Department of Surgery, China Medical University Beigang Hospital, Beigang, Taiwan, R.O.C.; \\ Departments of ${ }^{3}$ Medical Research, and ${ }^{7}$ Anesthesiology, \\ China Medical University Hospital, Taichung, Taiwan, R.O.C.; \\ ${ }^{4}$ Department of Biochemical Engineering and Environmental Sciences, \\ National Tsing Hua University, Hsinchu, Taiwan, R.O.C.; \\ ${ }^{5}$ Cardiovascular Center, Taichung Veterans General Hospital, Taichung, Taiwan, R.O.C.; \\ Departments of ${ }^{6}$ Biological Science and Technology, and ${ }^{8}$ Anesthesiology, \\ China Medical University, Taichung, Taiwan, R.O.C.; \\ ${ }^{9}$ Department of Chinese Medicine, Feng-Yuan Hospital, \\ Ministry of Health and Welfare, Executive Yuan, Taichung, Taiwan, R.O.C.; \\ ${ }^{10}$ General Education Center, Central Taiwan University of Science and Technology, Taichung, Taiwan, R.O.C.; \\ ${ }^{11}$ Department of Orthopaedics, Chang Bing Show-Chwan Memorial Hospital, Changhua, Taiwan, R.O.C.; \\ ${ }^{12}$ Department of Biotechnology, Asia University, Taichung, Taiwan, R.O.C.
}

\begin{abstract}
Background/Aim: Maslinic acid (MA), a pentacyclic triterpene extracted from wax-like coatings of olives, has been shown to reduce cancer cell number through induction of autophagy and apoptosis in many human cancer cells including human leukemia $H L-60$ cells. In the present study, we investigated whether or not MA affects immune responses in a leukemia mouse model. Materials and Methods: WEHI-3 cells were intraperitoneally (i.p.) injected
\end{abstract}

This article is freely accessible online.

\footnotetext{
*These Authors contributed equally to this work.

Correspondence to: Jing-Gung Chung, Ph.D., Department of Biological Science and Technology, China Medical University. No 91, Hsueh-Shih Road, Taichung, Taiwan, R.O.C. Tel: +886 422053366 ext. 8000, Fax: +886 422053764, e-mail: jgchung@mail.cmu.edu.tw Dr. Jr-Kai Chen, Attending Physician of Orthopaedics, Department of Orthopaedics, Chang Bing ShowChwan Memorial Hospital. No.6, Lugong Rd., Changhua, Taiwan, R.O.C. Tel: +886 47813888, e-mail: u9101046@hotmail.com
}

Key Words: Maslinic acid, leukemia WEHI-3 cells, macrophage, natural killer cells, immune responses. into normal $B A L B / c$ mice to develop leukemia. Mice were then treated by i.p. injection with MA at different doses $(0,8$, 16 and $32 \mathrm{mg} / \mathrm{kg}$ ) for 2 weeks. After treatment, all animals were weighed and blood, liver and spleen tissues were weighed. Blood or spleen both were used for determination of cell markers or phagocytosis, natural killer (NK) cell activities and $T$ - and $B$-cell proliferation, respectively, by using a flow cytometric assay. Results: MA did not significantly affect body, liver, and spleen weights. However, MA increased markers of T-cells (at $16 \mathrm{mg} / \mathrm{kg}$ treatment) and monocytes (at $32 \mathrm{mg} / \mathrm{kg}$ treatment), but reduced $B$-cell markers (at $8 \mathrm{mg} / \mathrm{kg}$ treatment); MA did not significantly affect cell marker of macrophages. Furthermore, MA increased phagocytosis by macrophages from peripheral blood mononuclear cells and peritoneal cavity at $32 \mathrm{mg} / \mathrm{kg}$ treatment and increased $N K$ cell activity at target cell:splenocyte ratio of 25:1 but did not affect B-and T-cell proliferation. Conclusion: MA increased immune responses by enhancing macrophage phagocytosis and NK cell activities in leukemic mice.

Leukemia, one of the main causes of death in humans worldwide, progresses through unregulated proliferation of immature blood cells (1). The 2008 revision of the World 
Health Organization (WHO) classified leukemia into acute myelomonocytic leukemia (AML) and chronic myelomonocytic leukemia (CML) (2). In Taiwan, about two individuals per 100,000,000 die of leukemia per year based on 2016 Taiwan Health and Welfare Report. CML is a clonal hematopoietic stem cell disorder with features overlapping those of myelodysplastic syndromes and myeloproliferative neoplasms (3). In patients with CML, about 15-30\% evolve into AML (4). AML is the most common acute leukemia in adults and its incidence increases with age (5) and the most common pediatric malignancy $(6,7)$. The incidence of AML is approximately four cases per 100,000, and the median age at diagnosis is 70 years (8). Currently, the clinical treatment for patients with leukemia is chemotherapy, however, this usually has a low efficacy and high toxicity (9). Therefore, numerous studies are focusing on the identification and development of new therapeutic agents from natural products owing to their wide range of biological activities, low toxicity and weak side-effects.

Many natural products have been clinically used for therapeutic agents. Maslinic acid (MA) is a pentacyclic triterpene acid present in dietary plants such as the olive (Olea europaea L.) (10) and is especially abundant in olive fruit skins. MA has many biological activities such as antiinflammatory (11), anti-oxidant $(11,12)$, antibacterial (13) and anti-HIV (14), anti-virus (15), anti-diabetogenic (16) and anticancer $(10,17-19)$ activities. In addition, MA also has anti-allodynic and analgesic properties via regulating cell metabolism and immune function (20).

Several molecular mechanisms for MA-induced cytotoxic effects have been demonstrated, such as activation of p38 MAPK pathway in MA-treated bladder cancer cells (21) and induction of apoptosis via the inhibition of the interleukin 6/Janus kinase/signal transducer and activator of transcription 3 (IL6/JAK/STAT3) signaling cascade in suppression of growth of human gastric cancer cells (22). More interestingly, studies showed the significant inhibitory activities of MA against human leukemia CCRF-CEM cells and its multidrug-resistant sub-line, CEM/ADR5000, with half-maximal inhibitory concentration $\left(\mathrm{IC}_{50}\right)$ values in the range of 7.1 to $29.7 \mu \mathrm{M}$ (23). MA exerted parasitostatic action and has been recognized as favoring the development of more effective immune responses (24). However, the molecular mechanisms of MA action in immune responses are still not clear. In this study, we investigated the MAinduced effects on immune responses in an in vivo mouse model of leukemia.

\section{Materials and Methods}

Materials and reagents. MA, dimethyl sulfoxide (DMSO), Lglutamine and penicillin-streptomycin were purchased from SigmaAldrich Corp. (St. Louis, MO, USA). Fetal bovine serum (FBS),
Iscove's modified Dulbecco's medium (IMDM) and RPMI-1640 culture medium were obtained from Gibco Life Technologies (Carlsbad, CA, USA). Anti-CD3 (T-cell marker), CD19 (B-cell marker), CD11b (monocyte marker) and Mac-3 (macrophage marker) were obtained from BD Biosciences Pharmingen Inc. (San Diego, CA, USA). Tissue-culture plastic ware was obtained from TPP (Traisadingen, Switzerland). MA was dissolved in DMSO as stock solution in a $50 \mathrm{ml}$ tube for further experiments and kept at $-20^{\circ} \mathrm{C}$ in the dark.

Cell culture. Murine myelomonocytic leukemia cells (WEHI-3 cells) and YAC-1 were obtained from the Food Industry Research and Development Institute (Hsinchu, Taiwan, R.O.C.). About $1 \times 10^{6}$ cells/ml in IMDM or RPMI-1640 medium supplemented with $10 \%$ fetal bovine serum, 100 units $/ \mathrm{ml}$ penicillin, $100 \mu \mathrm{g} / \mathrm{ml}$ streptomycin and $2 \mathrm{mM} \mathrm{L}$-glutamine were placed in $75 \mathrm{~cm}^{2}$ tissue culture flasks under humidified $5 \% \mathrm{CO}_{2}$ at $37^{\circ} \mathrm{C}$ as previously described (25).

Male BALB/c mice. Forty-eight male BALB/c mice at 5 weeks old, weighing approximately $22-25 \mathrm{~g}$ each, were purchased from the National Laboratory Animal Center (Taipei, Taiwan, R.O.C.). All mice were housed under standard conditions of $12 \mathrm{~h}$ light/dark cycles and temperature $\left(25^{\circ} \mathrm{C}\right)$ in the Animal Housing Facility Center of China Medical University (Taichung, Taiwan). All mice were fed ad libitum on a commercial diet (Prolab RMH 2500; LabDiet, PMI Nutrition, Brentwood, MO, USA). The animal study project was reviewed and approved by the Institutional Animal Care and Use Committee of China Medical University (approval ID: 2017-009-1). In vivo experiments were carried out in accordance with the institutional animal ethical guidelines of the China Medical University as described previously (25).

Treatment of animals with MA. The in vivo immune responses of MA were performed by analysis of leukocyte populations and associated activities as previously described (25). In brief, 48 mice were randomly divided into six groups $(\mathrm{n}=8)$. Group I mice received normal diet as control. In the other five groups, mice were inoculated i.p. with WEHI-3 leukemia cells $\left(8 \times 10^{4}\right.$ cells/mouse $)$ to generate leukemic mice. Group II mice received with normal diet as positive control. Group III mice received all-trans retinoic acid (ATRA), used clinically for therapy of acute promyelocytic leukemia, ( $5 \mathrm{mg} / \mathrm{kg}$; Sigma-Aldrich Corp., St. Louis, MO, USA) in olive oil by oral gavage every 2 days, as a control. Group IV-VI mice received MA $(8,16$, and $32 \mathrm{mg} / \mathrm{kg}$, respectively) in DMSO by i.p. injection every 2 days. All mice were weighed every 2 days. The flowchart of the animal experiment is summarized in Figure 1. At day 21, all mice were weighed and sacrificed by euthanasia with $\mathrm{CO}_{2}$ as described previously (25) and blood, liver and spleen tissues were collected.

Immunofluorescence staining for cell-surface markers. At the end of treatment, all mice were individually weighed and blood samples were collected. For isolating leukocytes, a 200- $\mu$ l blood sample from each animal was lysed for destroying red blood cells with $1 \times$ Pharm Lyse ${ }^{\mathrm{TM}}$ lysing buffer (BD Biosciences; San Jose, CA, USA) as the guideline from BD Biosciences. After centrifugation, isolated leukocytes were individually stained by phycoerythrin (PE)labeled anti-mouse CD3, PE-labeled anti-mouse CD19, fluorescein isothiocyanate (FITC)-labeled anti-mouse CD11b and FITC-labeled anti-mouse Mac-3 antibodies for $1 \mathrm{~h}$ at $4^{\circ} \mathrm{C}$. All samples were 


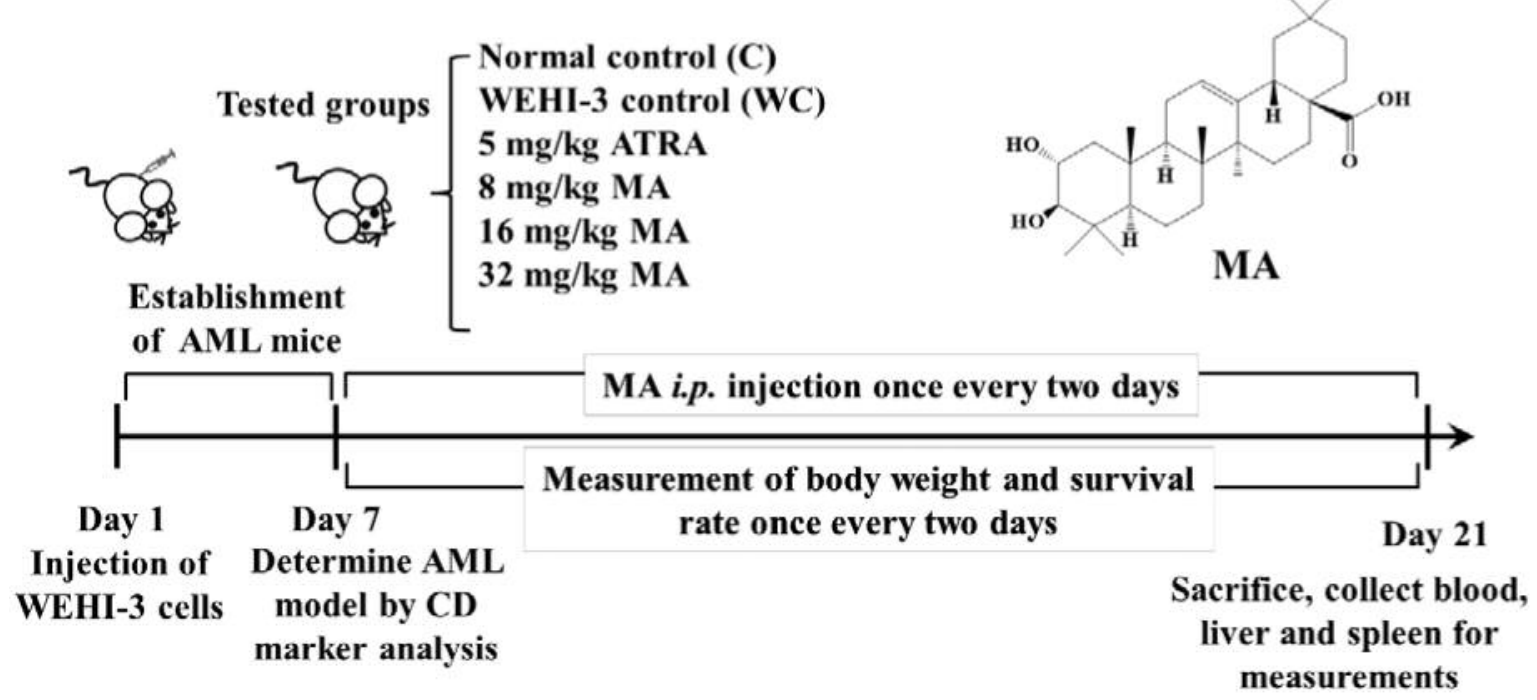

Figure 1. The procedure of establishment of leukemic mice and maslinic acid (MA) treatment. ATRA: All-trans retinoic acid (ATRA); AML: acute myelomonocytic leukemia.

analyzed by flow cytometry for determining the percentage of cell markers and quantified using CellQuest ${ }^{\mathrm{TM}}$ Programs (Version 5.2.1, BD Biosciences, San Jose, CA, USA), as previously described (25).

Measurement of macrophage phagocytosis. Macrophage phagocytosis was measured by flow cytometric assay as described previously (25). In brief, macrophages were isolated from peripheral blood mononuclear cells (PBMCs) and peritoneum of each mice from each treatment group. Macrophages were placed in plates and $50 \mu \mathrm{l}$ of Escherichia coli-FITC were added to the cells according to PHAGOTEST ${ }^{\circledR}$ kit manufacturer's instructions (ORPEGEN Pharma Gesellschaft für biotechnologische, Heidelberg, Germany) and mixed well. All samples were analyzed for phagocytosis using flow cytometry and then were quantified by CellQuest ${ }^{\mathrm{TM}}$ Programs (BD Biosciences) as described previously (25).

Measurement of natural killer (NK) cell cytotoxic activity. Isolated splenocytes $\left(1 \times 10^{5}\right.$ cells/well) in RPMI-1640 medium were placed in a 96-well plate. The target cells (YAC-1 cells; Food Industry Research and Development Institute, Hsinchu, Taiwan, R.O.C.) $\left(2.5-5 \times 10^{6}\right.$ cells) in PKH-67/Dil.C buffer (Sigma-Aldrich Corp.) were added to the cells and mixed thoroughly for $2 \mathrm{~min}$ at $25^{\circ} \mathrm{C}$. PBS $(0.2 \mathrm{ml})$ was added to each well for $1 \mathrm{~min}$ and $0.4 \mathrm{ml}$ medium were added and plates were incubated for $10 \mathrm{~min}$. At the end of incubation, samples were centrifuged at $260 \times g$ for $2 \mathrm{~min}$. NK cell cytotoxic activity from each treatment was measured by flow cytometry as described elsewhere (25).

Measurement of $T$ - and B-cell proliferation. Splenocytes $\left(1 \times 10^{5}\right.$ cells/well) in $100 \mu$ l PBS from each animal were placed in a 96-well plate containing $100 \mu \mathrm{l}$ of RPMI-1640 medium. For T-cell proliferation examination, concanavalin A (Con A, $0.5 \mu \mathrm{g} / \mathrm{ml}$; SigmaAldrich Corp.) was added to the cells to stimulate for 3 days. For Bcell proliferation examination, lipopolysaccharide (LPS, $1 \mu \mathrm{g} / \mathrm{ml}$;
Sigma-Aldrich Corp.) was added to the cells to stimulate for 5 days. Both samples were measured by using CellTiter 96 AQueous One Solution Cell Proliferation Assay kit (Promega, Madison, WI, USA) as previously described (25).

Statistical analysis. All values are expressed as mean \pm standard error (S.D.). Comparisons between groups were analyzed by one-way ANOVA analysis of variance and Tukey test for multiple comparisons (SigmaPlot for Windows version 12.0; Systat Software, Inc., San Jose, CA, USA). A value of $p<0.05$ was considered to indicate a statistically significant difference.

\section{Results}

Effects of MA on body, liver and spleen weights of leukemic $B A L B / c$ mice. After treatment with MA, blood, liver and spleen were collected from the six groups mice. Representative animal appearances and body weights are shown in Figure $2 \mathrm{~A}$ and $\mathrm{B}$, respectively; there were no significant differences between groups. The survival rate of leukemia-bearing mice was markedly reduced in the group treated with $32 \mathrm{mg} / \mathrm{kg}$ MA (Figure 2C). Based on these observations, MA may have effective anti-leukemic activity in vivo. Furthermore, representative liver and spleen weights are shown Figure 2D and E. The results indicate that MA slightly reduced the liver weight (Figure 2D) and spleen weight (Figure 2E) at low doses ( 8 and $16 \mathrm{mg} / \mathrm{kg}$, respectively) when compared with the WEHI-3 control (WC) group.

Effects of MA on cells markers of white blood cells of leukemic $B A L B / c$ mice. Blood samples were collected and 
A
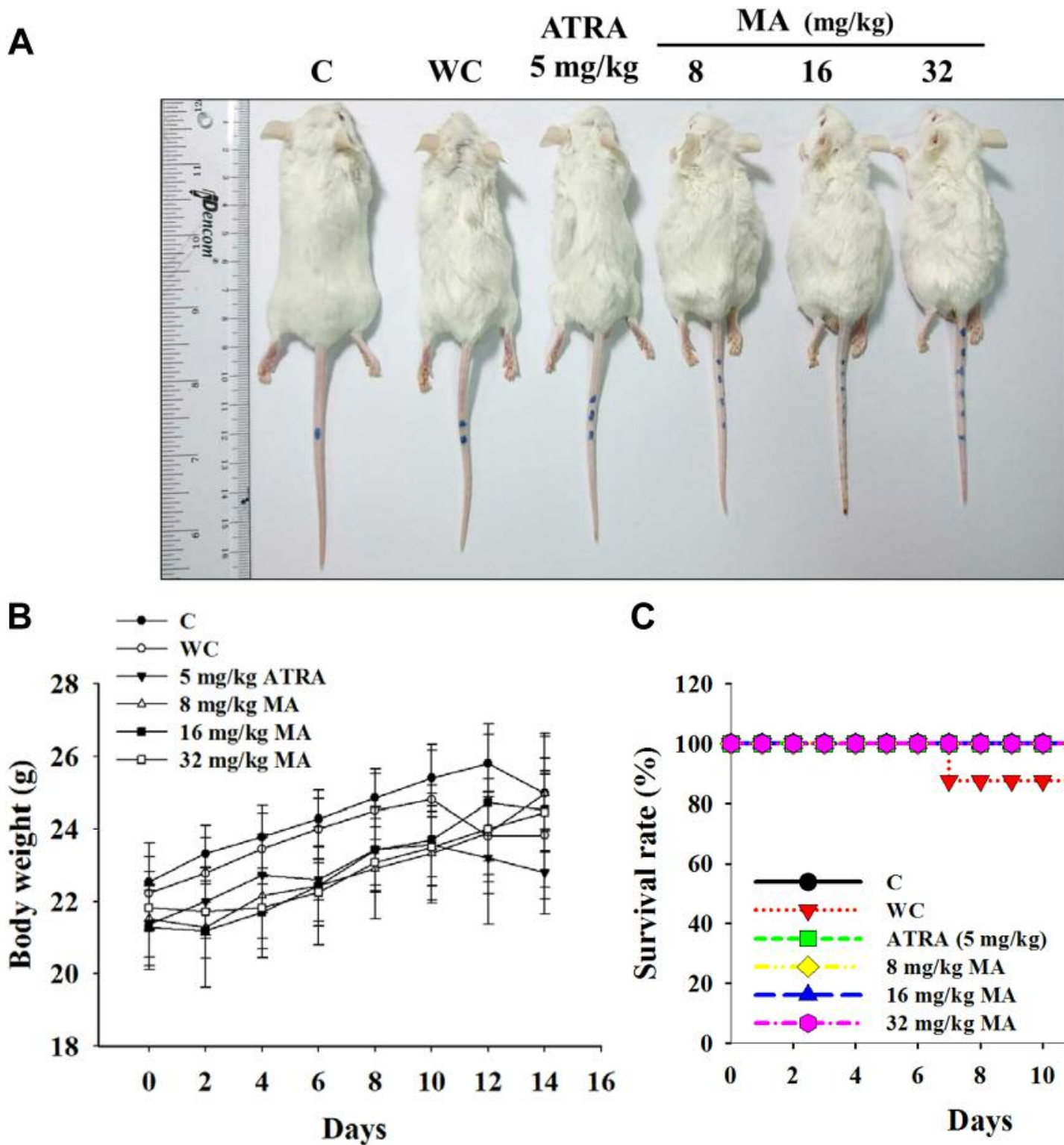

C

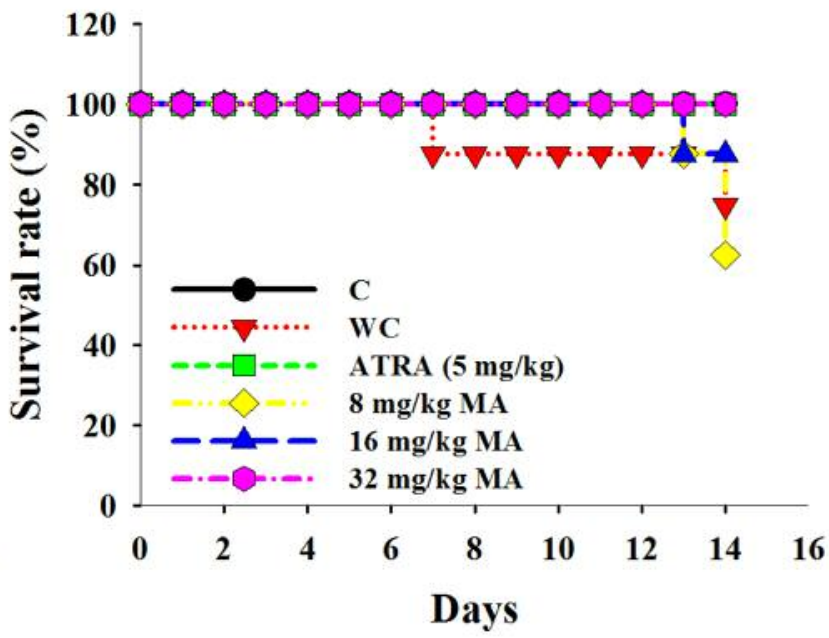

D
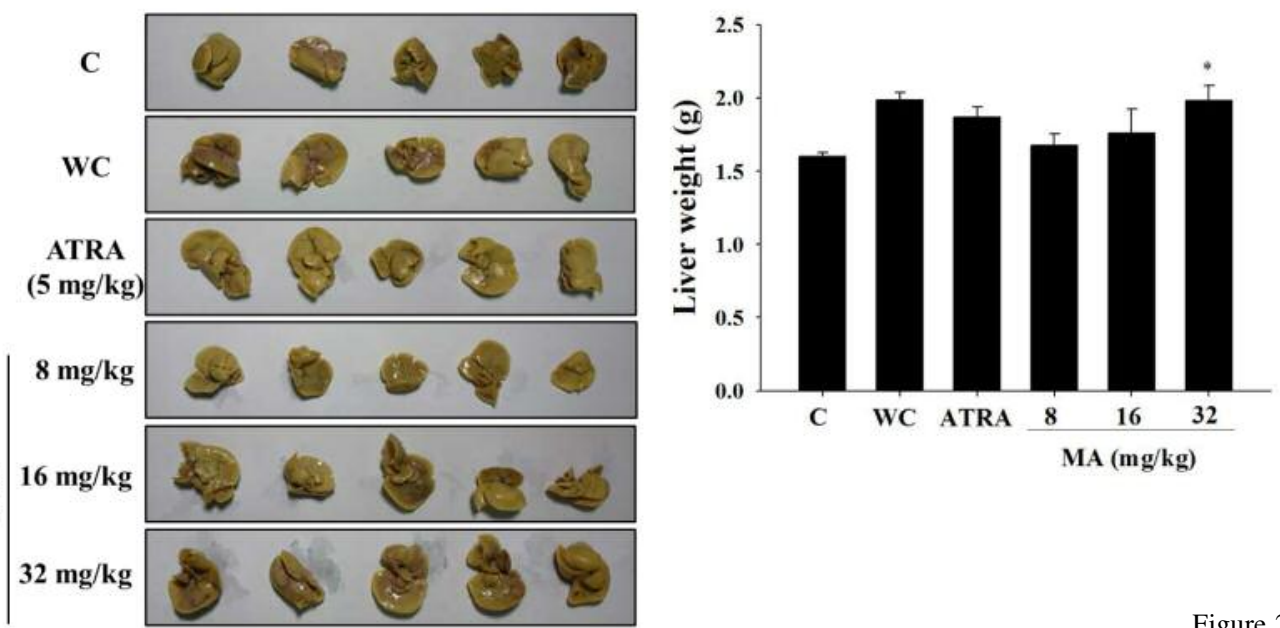

Figure 2. Continued 

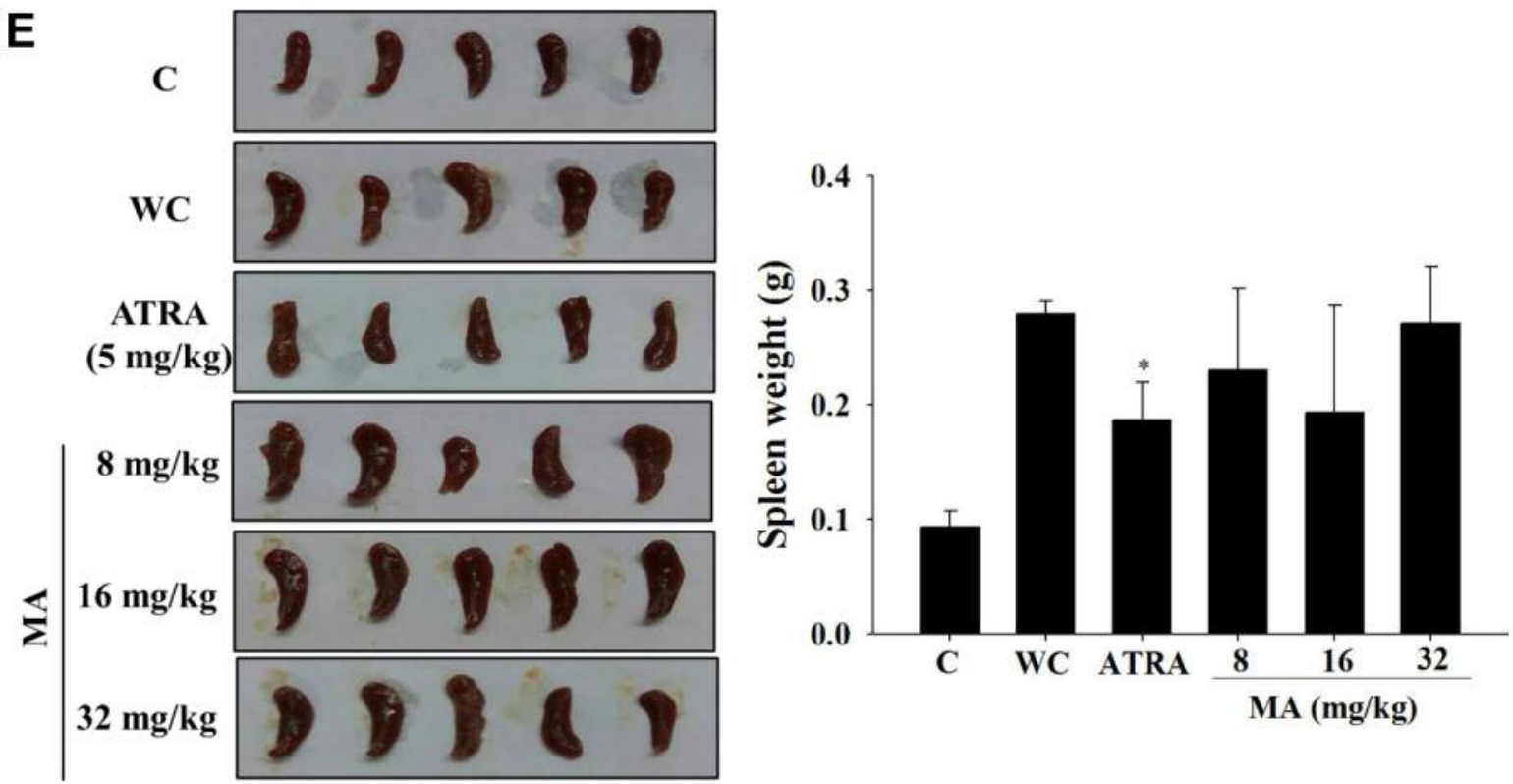

Figure 2. Effects of maslinic acid (MA) on the bodyweight, liver and spleen weight of leukemic BALB/c mice. Group I was treated with normal diet and acted as control (C). Group II-VI mice were intraperitoneally injected with WEHI-3 cells and then were divided into groups. Group II, as WEHI-3 control (WC), was treated with normal diet. Group III was treated with $5 \mathrm{mg} / \mathrm{kg}$ of all-trans retinoic acid (ATRA). Group IV-VI were treated with 8,16 , and $32 \mathrm{mg} / \mathrm{kg}$ of MA, respectively. All animals were treated for 8 days. The total body, liver, and spleen weights and survival rates were measured every 2 days. Representative images of animal appearance $(A)$, body weight $(B)$, survival rate $(C)$, and liver $(D)$ and spleen $(E)$ weights are presented. *Significantly different at $p<0.05$ from WEHI-3 control group.

stained with anti-CD3,-CD19, -CD11b and -Mac-3. The results indicate that MA slightly increased $\mathrm{CD}^{+} \mathrm{T}$-cells at 16 $\mathrm{mg} / \mathrm{kg}$ treatment (Figure 3A), but significantly reduced CD19 ${ }^{+}$ B-cells (Figure 3B) at $8 \mathrm{mg} / \mathrm{kg}$ treatment. MA also nonsignificantly increased $\mathrm{CD}_{11 \mathrm{~b}^{+}}$(Figure 3B; $32 \mathrm{mg} / \mathrm{kg}$ MA treatment) but slightly reduced $\mathrm{Mac}-3^{+}$macrophages (Figure $3 \mathrm{D} ; 8 \mathrm{mg} / \mathrm{kg}$ treatment) when compared to the WC group.

Effects of MA on macrophage phagocytosis from PBMC and peritoneal cavity of leukemic BALB/c mice. Macrophages isolated from PBMCs and the peritoneal cavity were used to measure the levels of phagocytosis by flow cytometry. MA treatment at 8,16 , and $32 \mathrm{mg} / \mathrm{kg}$ significantly increased phagocytosis by macrophage from PBMCs (Figure 4A) and from the peritoneal cavity at $32 \mathrm{mg} / \mathrm{kg}$ (Figure 4B).

Effects of MA on cytotoxic activity of NK cells from leukemic $B A L B / c$ mice. Splenocytes isolated from each treatment group were used to measure NK cell activities using YAC-1 cells as target cells. The results indicate that YAC-1 cells were killed by $\mathrm{NK}$ cells at $8 \mathrm{mg} / \mathrm{kg}$ MA that indicated that MA increased NK cell activities at target cell:splenocyte ratio of 25:1 when compared to the WC group (Figure 5).
Effects of MA on proliferation of B-and T-cells of leukemic $B A L B / c$ mice. Splenocytes isolated from each treatment group were used for measuring $\mathrm{B}$ - and T-cell proliferation using Con A (T-cell mitogen) and LPS (B-cell mitogen), respectively, for stimulation. Results shown in Figure 6 indicate that MA at $32 \mathrm{mg} / \mathrm{kg}$ treatment without Con A stimulation significantly reduced T-cell proliferation (Figure 6A). However, none of the treatments significantly affected B- and T-cell proliferation (Figure 6A and B) after stimulation when compared with the WC group.

\section{Discussion}

Numerous studies have shown that MA induces cytotoxic effects on human cancer cell lines through the induction of cell apoptosis including human leukemia HL-60 cells (21, 26), however, there is no available information to show the effects of MA on mouse leukemia in vivo. Another reason for this experiment is that MA has been suggested to represent a new class of anti-malarial compound based on its parasitostatic action, which favors the development of more effective immune responses (24). Murine WEHI-3 cells were injected into normal $\mathrm{BALB} / \mathrm{c}$ mice to generate an animal model of leukemia that is a well-known protocol. 
A

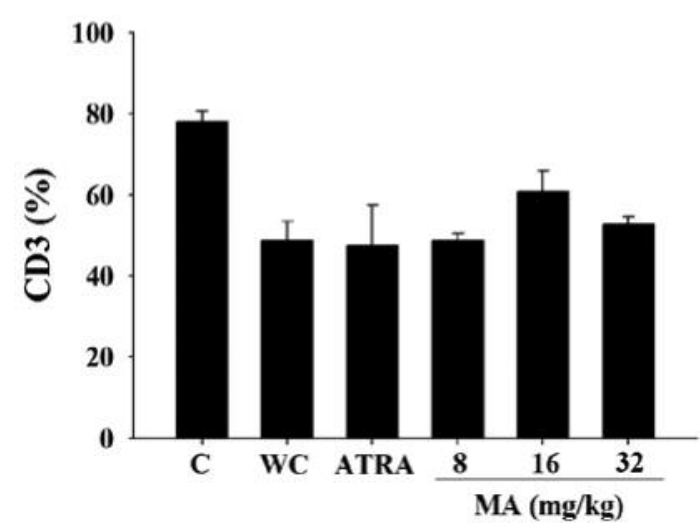

C

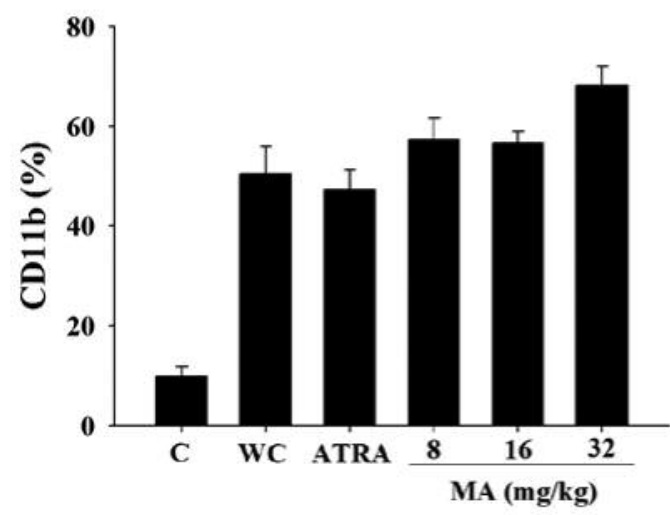

B

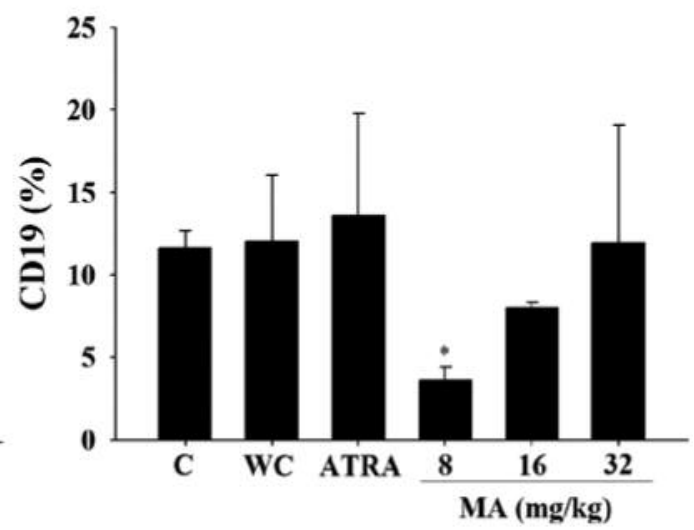

D

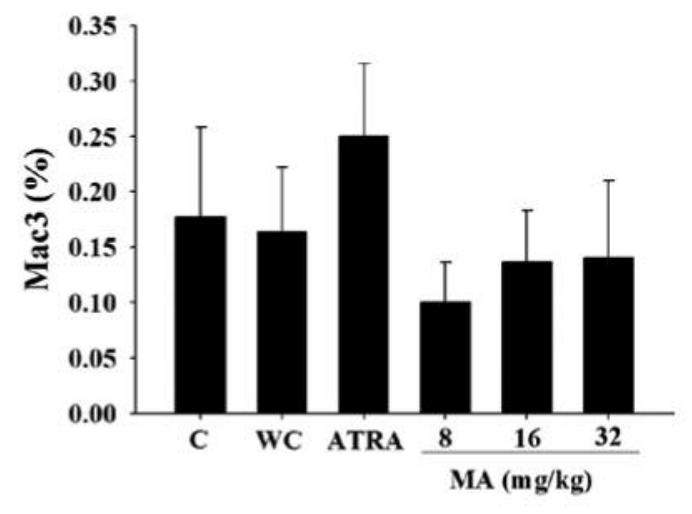

Figure 3. Effects of maslinic acid (MA) on levels of cell markers in white blood cells from leukemic BALB/c mice. Group I was treated with normal diet and acted as control (C). Group II-VI mice were intraperitoneally injected with WEHI-3 cells and then were divided into groups. Group II, as WEHI-3 control (WC), was treated with normal diet. Group III was treated with $5 \mathrm{mg} / \mathrm{kg}$ of all-trans retinoic acid (ATRA). Groups IV-VI were treated with 8, 16, and $32 \mathrm{mg} / \mathrm{kg}$ of MA, respectively. All animals were treated for 8 days. Blood was collected from each animal and analyzed for cell markers (A: CD3; B: CD19; C: CD11b; D: Mac-3) by flow cytometry as described in the Materials and Methods. *Significantly different at $p<0.05$ from WEHI-3 control group.

MA displays low toxicity towards non-tumoral cells and can be regarded as safe in therapeutic applications. Literature reported that MA stimulated the growth of rainbow trouts (Oncorhynchus mykiss) (16, 27) by affecting protein synthesis, and MA increased the survival rate of mice from $20 \%$ to $80 \%$ and led to immune protection after lethal Plasmodium yoelii infection $(28,29)$. In the present study, as shown in Figure 2B, MA slightly increased the body weight of leukemic mice and did not induce toxic effects during the treatment periods. The results also showed that MA treatment at a high dose $(32 \mathrm{mg} / \mathrm{kg})$ increased the survival rate of leukemia mice (Figure 2C), but the detailed mechanism underlying this remains to be clarified.

Cell population assay from blood samples of leukemic mice showed that MA slightly increased the expressions of T-cell (CD3, Figure 3A) and monocyte (CD11b, Figure 3C) markers at 16 and $32 \mathrm{mg} / \mathrm{kg}$ treatment, respectively, but significantly reduced the expression of CD19 (B-cells, Figure 3B). T-Cells $\left(\mathrm{CD}^{+}\right)$, B-cells $\left(\mathrm{CD} 19^{+}\right)$and monocytes $\left(\mathrm{CD} 11 \mathrm{~b}^{+}\right)$play critical roles in immune responses. $\mathrm{CD} 3$ is expressed in the membrane and cytoplasm of normal and neoplastic T-cells (30). CD19 plays roles in antigenindependent development as well as in immunoglobulininduced activation of B-cells. CD19 is, thus, critical for the body to mount an optimal immune response. CD19 is thought to play dual roles in B-cell activation (31). CD11b plays a role in regulating leukocyte adhesion and migration and modulates various aspects of immune responses (32). Much evidence has shown that several types of white blood cell are involved in producing immune responses $(33,34)$. We also found that MA increased immune responses in leukemic $\mathrm{BALB} / \mathrm{c}$ mice in vivo. 
A

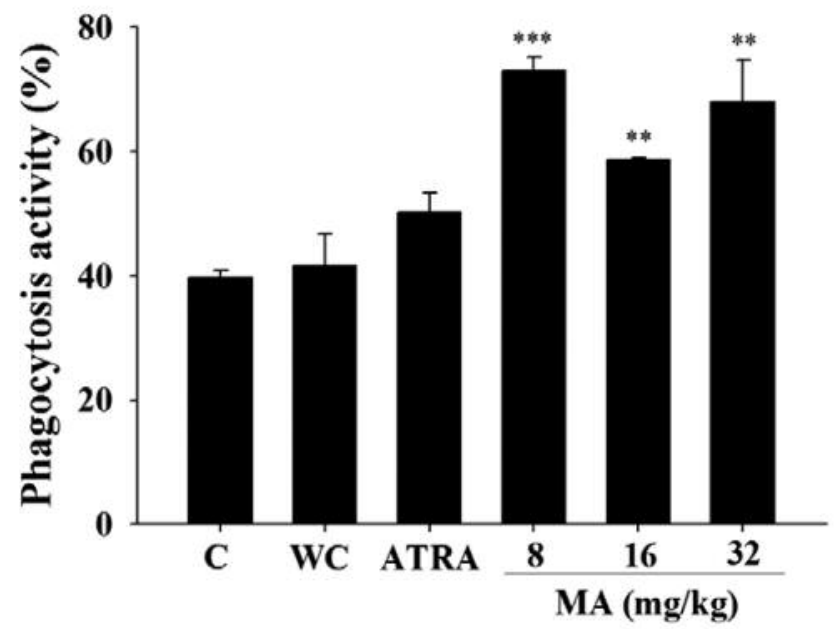

B

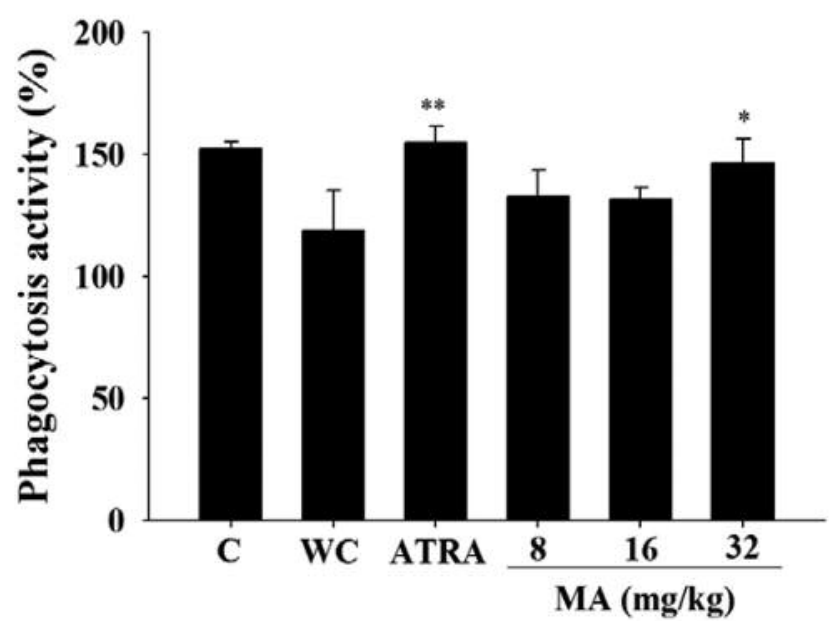

Figure 4. Effects of maslinic acid (MA) on phagocytosis by macrophage from peripheral blood mononuclear cells (PBMCs) (A) and peritoneal cavity $(B)$ of leukemic BALB/c mice. Group I was treated with normal diet and acted as control $(C)$. Group II-VI mice were intraperitoneally injected with WEHI-3 cells and then were divided into groups. Group II, as WEHI-3 control (WC), was treated with normal diet. Group III was treated with $5 \mathrm{mg} / \mathrm{kg}$ of all-trans retinoic acid (ATRA). Group IV-VI were treated with 8, 16, and $32 \mathrm{mg} / \mathrm{kg}$ of MA, respectively. All animals were treated for 8 days. Blood samples were collected from mice then macrophages were isolated from PBMCs and peritoneum of each mouse. Macrophage phagocytosis was measured by flow cytometry and quantified by CellQuest as described in the Materials and Methods. Significantly different at $* p<0.05, * * p<0.01$ and $* * * p<0.001$ from WEHI-3 control group.

In the present study, E. coli-FITC was used as a target for examining macrophage phagocytosis (25) and YAC-1 cells as a target for NK cell activity $(35,36)$. Our results showed that MA $(8,16,32 \mathrm{mg} / \mathrm{kg})$ increased phagocytosis by macrophages from PBMCs (Figure 4A) and the peritoneal cavity (32 mg/kg) (Figure 4B). Numerous studies have demonstrated that in response to microenvironmental signals, macrophages have a great plasticity which allows them to differentiate into several functional states (37-39). Many studies examined the roles of immune cell subtypes and their capacity for function or dysfunction in the tumor microenvironment $(40,41)$. We also found that MA treatment at $8 \mathrm{mg} / \mathrm{kg}$ increased NK cell activity. It has been suggested that the stimulation of NK cell cytotoxicity may lead to an increased immune response (42).

In conclusion, based on these results, we suggest that MAmodulated immune responses may occur through increasing CD19 and CD11 markers (populations), and macrophage phagocytotic activity, and promoting NK cell cytotoxicity in leukemic mice in vivo.

\section{Acknowledgements}

This work was supported by grant RD106002 from Chang Bing Show Chwan Memorial Hospital, Changhua, Taiwan, and by grant CMUBH R106-002 from China Medical University Beigang Hospital, Beigang, Yunlin, Taiwan. Experiments and data analysis were performed in part through the use of the Medical Research

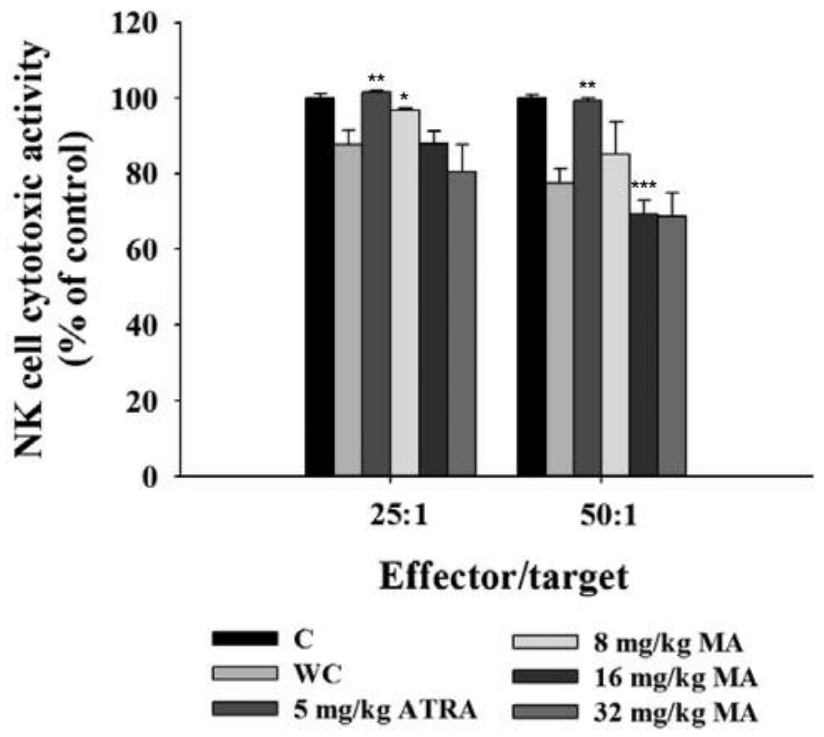

Figure 5. Effects of maslinic acid (MA) on cytotoxic activity of natural killer (NK) cells in leukemic BALB/c mice. Group I was treated with normal diet and acted as control (C). Group II-VI mice were intraperitoneally injected with WEHI-3 cells and then were divided into groups. Group II, as WEHI-3 control (WC), was treated with normal diet. Group III was treated with $5 \mathrm{mg} / \mathrm{kg}$ of all-trans retinoic acid (ATRA). Groups IV-VI were treated with 8, 16, and $32 \mathrm{mg} / \mathrm{kg}$ of MA, respectively. All animals were treated for 8 days. NK cell cytotoxic activity was measured by flow cytometry as described in the Materials and Methods. Significantly different at $* p<0.05, * * p<0.01$ and $* * * p<0.001$ from WEHI-3 control group. 


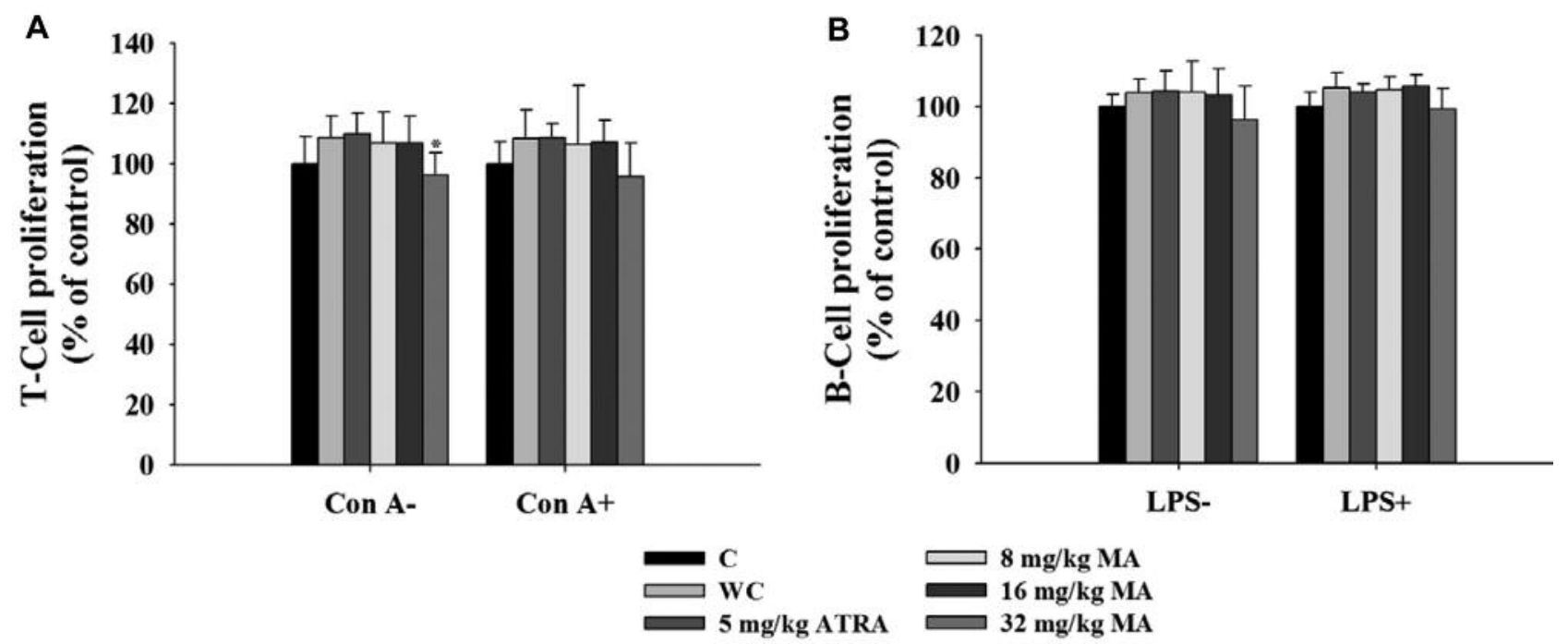

Figure 6. Effects of maslinic acid (MA) on B-and T-cell proliferation in leukemic BALB/c mice. Group I was treated with normal diet and acted as control (C). Group II-VI mice were intraperitoneally injected with WEHI-3 cells and then were divided into groups. Group II, as WEHI-3 control (WC), was treated with normal diet. Group III was treated with $5 \mathrm{mg} / \mathrm{kg}$ of all-trans retinoic acid (ATRA). Group IV-VI were treated with 8, 16, and $32 \mathrm{mg} / \mathrm{kg}$ of MA, respectively. All animals were treated for 8 days. Isolated splenocytes were pretreated with concanavalin A (Con A) for T-cell (A) and with lipopolysaccharide (LPS) for B-cell (B) proliferation, respectively, and then analyzed by flow cytometry as described in the Materials and Methods. *Significantly different at $p<0.05$ from WEHI-3 control group.

Core Facilities Center, Office of Research \& Development at China Medical University, Taichung, Taiwan, R.O.C.

\section{References}

1 Alabsi AM, Ali R, Ideris A, Omar AR, Bejo MH, Yusoff K and Ali AM: Anti-leukemic activity of Newcastle disease virus strains AF2240 and V4-UPM in murine myelomonocytic leukemia in vivo. Leuk Res 36: 634-645, 2012.

2 Vardiman JW, Thiele J, Arber DA, Brunning RD, Borowitz MJ, Porwit A, Harris NL, Le Beau MM, Hellstrom-Lindberg E, Tefferi A and Bloomfield CD: The 2008 revision of the World Health Organization (WHO) classification of myeloid neoplasms and acute leukemia: Rationale and important changes. Blood 114: 937-951, 2009.

3 Patnaik MM and Tefferi A: Chronic myelomonocytic leukemia: 2018 Update on diagnosis, risk stratification and management. Am J Hematol 93: 824-840, 2018.

4 Germing U, Kundgen A and Gattermann N: Risk assessment in chronic myelomonocytic leukemia (CMML). Leuk Lymphoma 45: 1311-1318, 2004.

5 Briot $\mathrm{T}$, Roger $\mathrm{E}$, Thepot $\mathrm{S}$ and Lagarce $\mathrm{F}$ : Advances in treatment formulations for acute myeloid leukemia. Drug Discov Today, 2018. https://doi.org/10.1016/j.drudis.2018.05.040.

6 Diezi M, Garcia E, Weid N and Beck-Popovic M: No role for cerebrospinal fluid myelin basic protein levels in patients treated for childhood acute lymphoblastic leukemia. J Pediatr Hematol Oncol 31: 393-397, 2009.

7 Puckett Y and Chan O: Cancer, Leukemia, Lymphocytic, Acute (ALL). In: StatPearls. Treasure Island (FL): StatPearls Publishing LLC., 2018.
8 Smith A, Howell D, Patmore R, Jack A and Roman E: Incidence of haematological malignancy by sub-type: a report from the Haematological Malignancy Research Network. Br J Cancer 105: 1684-1692, 2011.

9 De Kouchkovsky I and Abdul-Hay M: Acute myeloid leukemia: A comprehensive review and 2016 update. Blood Cancer J 6: e441, 2016.

10 Reyes-Zurita FJ, Rufino-Palomares EE, Lupianez JA and Cascante M: Maslinic acid, a natural triterpene from Olea europaea L., induces apoptosis in HT29 human colon-cancer cells via the mitochondrial apoptotic pathway. Cancer Lett 273: 44-54, 2009.

11 Aladedunye FA, Okorie DA and Ighodaro OM: Anti-inflammatory and antioxidant activities and constituents of Platostoma africanum P. Beauv. Nat Prod Res 22: 1067-1073, 2008.

12 Sultana $\mathrm{N}$ and Lee NH: Antielastase and free radical-scavenging activities of compounds from the stems of Cornus kousa. Phytother Res 21: 1171-1176, 2007.

13 Pavel IZ, Danciu C, Oprean C, Dehelean CA, Muntean D, Csuk R and Muntean DM: In vitro evaluation of the antimicrobial ability and cytotoxicity on two melanoma cell lines of a benzylamide derivative of maslinic acid. Anal Cell Pathol 2016: 2787623, 2016.

14 Parra A, Rivas F, Lopez PE, Garcia-Granados A, Martinez A, Albericio F, Marquez N and Munoz E: Solution-and solid-phase synthesis and anti-HIV activity of maslinic acid derivatives containing amino acids and peptides. Bioorg Med Chem 17: 1139-1145, 2009.

15 Scalon Cunha LC, Andrade e Silva ML, Cardoso Furtado NA, Vinholis AH, Martins CH, da Silva Filho AA and Cunha WR: Antibacterial activity of triterpene acids and semi-synthetic derivatives against oral pathogens. Z Naturforsch C 62: 668-672, 2007. 
16 Fernandez-Navarro M, Peragon J, Amores V, De La Higuera M and Lupianez JA: Maslinic acid added to the diet increases growth and protein-turnover rates in the white muscle of rainbow trout (Oncorhynchus mykiss). Comp Biochem Physiol C Toxicol Pharmacol 147: 158-167, 2008.

17 Chang T, Li X, Chen X, Zhang L, Yang F, Li Z and Li J: Maslinic acid activates mitochondria-dependent apoptotic pathway in cardiac carcinoma. Clin Invest Med 37: E217-224, 2014.

18 Rufino-Palomares EE, Reyes-Zurita FJ, Garcia-Salguero L, Mokhtari K, Medina PP, Lupianez JA and Peragon J: Maslinic acid, a triterpenic anti-tumoural agent, interferes with cytoskeleton protein expression in HT29 human colon-cancer cells. J Proteomics 83: 15-25, 2013.

19 Park SY, Nho CW, Kwon DY, Kang YH, Lee KW and Park JH: Maslinic acid inhibits the metastatic capacity of DU145 human prostate cancer cells: Possible mediation via hypoxia-inducible factor-1alpha signalling. Br J Nutr 109: 210-222, 2013.

20 Nieto FR, Cobos EJ, Entrena JM, Parra A, Garcia-Granados A and Baeyens JM: Antiallodynic and analgesic effects of maslinic acid, a pentacyclic triterpenoid from Olea europaea. J Nat Prod 76: 737-740, 2013.

21 Zhang S, Ding D, Zhang X, Shan L and Liu Z: Maslinic acid induced apoptosis in bladder cancer cells through activating p38 MAPK signaling pathway. Mol Cell Biochem 392: 281-287, 2014.

22 Wang D, Tang S and Zhang Q: Maslinic acid suppresses the growth of human gastric cells by inducing apoptosis via inhibition of the interleukin- 6 mediated Janus kinase/signal transducer and activator of transcription 3 signaling pathway. Oncol Lett 13: 4875-4881, 2017.

23 Wang YF, Lai GF, Efferth T, Cao JX and Luo SD: New glycosides from Tetracentron sinense and their cytotoxic activity. Chem Biodivers 3: 1023-1030, 2006.

24 Moneriz C, Marin-Garcia P, Bautista JM, Diez A and Puyet A: Parasitostatic effect of maslinic acid. II. Survival increase and immune protection in lethal Plasmodium yoelii-infected mice. Malar J 10: 103, 2011.

25 Shang HS, Shih YL, Chen CP, Lee MH, Lu HF, Chou PY, Liao NC, Chen YL, Hsueh SC and Chung JG: Laminarin promotes immune responses and normalizes glutamic oxaloacetic transaminase and glutamic pyruvic transaminase levels in leukemic mice in vivo. In Vivo 32: 783-790, 2018.

26 Uto T, Sakamoto A, Tung NH, Fujiki T, Kishihara K, Oiso S, Kariyazono H, Morinaga O and Shoyama Y: Anti-proliferative activities and apoptosis induction by triterpenes derived from Eriobotrya japonica in human leukemia cell lines. Int J Mol Sci 14: 4106-4120, 2013

27 Fernandez-Navarro M, Peragon J, Esteban FJ, de la Higuera M and Lupianez JA: Maslinic acid as a feed additive to stimulate growth and hepatic protein-turnover rates in rainbow trout (Oncorhynchus mykiss). Comp Biochem Physiol C Toxicol Pharmacol 144: 130-140, 2006.

28 Juan ME, Planas JM, Ruiz-Gutierrez V, Daniel H and Wenzel U: Antiproliferative and apoptosis-inducing effects of maslinic and oleanolic acids, two pentacyclic triterpenes from olives, on HT29 colon cancer cells. Br J Nutr 100: 36-43, 2008.
29 De Pablos LM, Gonzalez G, Rodrigues R, Garcia Granados A, Parra A and Osuna A: Action of a pentacyclic triterpenoid, maslinic acid, against Toxoplasma gondii. J Nat Prod 73: 831$834,2010$.

30 Chetty R and Gatter K: CD3: structure, function, and role of immunostaining in clinical practice. J Pathol 173: 303-307, 1994.

31 Wang K, Wei G and Liu D: CD19: A biomarker for B-cell development, lymphoma diagnosis and therapy. Exp Hematol Oncol 1: 36, 2012.

32 Zheng C, Yang Q, Xu C, Shou P, Cao J, Jiang M, Chen Q, Cao G, Han Y, Li F, Cao W, Zhang L, Zhang L, Shi Y and Wang Y: $\mathrm{CD} 11 \mathrm{~b}$ regulates obesity-induced insulin resistance via limiting alternative activation and proliferation of adipose tissue macrophages. Proc Natl Acad Sci USA 112: E7239-7248, 2015.

33 Nussing S, Sant S, Koutsakos M, Subbarao K, Nguyen THO and Kedzierska K: Innate and adaptive T-cells in influenza disease. Front Med 12: 34-47, 2018.

34 Nicholson LB: The immune system. Essays Biochem 60: 275301, 2016.

35 Yeh MY, Shih YL, Chung HY, Chou J, Lu HF, Liu CH, Liu JY, Huang WW, Peng SF, Wu LY and Chung JG: Chitosan promotes immune responses, ameliorating total mature white blood cell numbers, but increases glutamic oxaloacetic transaminase and glutamic pyruvic transaminase, and ameliorates lactate dehydrogenase levels in leukemia mice in vivo. Mol Med Rep 16: 2483-2490, 2017.

36 Santoni A, Zingoni A, Cerboni C and Gismondi A: Natural killer (NK) cells from killers to regulators: distinct features between peripheral blood and decidual NK cells. Am J Reprod Immunol 58: 280-288, 2007

37 Arpinati $M$ and Curti A: Immunotherapy in acute myeloid leukemia. Immunotherapy 6: 95-106, 2014.

38 Tarique AA, Logan J, Thomas E, Holt PG, Sly PD and Fantino E: Phenotypic, functional, and plasticity features of classical and alternatively activated human macrophages. Am J Respir Cell Mol Biol 53: 676-688, 2015.

39 Lavin Y, Mortha A, Rahman A and Merad M: Regulation of macrophage development and function in peripheral tissues. Nat Rev Immunol 15: 731-744, 2015.

40 Chang JH, Jiang Y and Pillarisetty VG: Role of immune cells in pancreatic cancer from bench to clinical application: An updated review. Medicine 95: e5541, 2016.

41 Law AM, Lim E, Ormandy CJ and Gallego-Ortega D: The innate and adaptive infiltrating immune systems as targets for breast cancer immunotherapy. Endocr Relat Cancer 24: R123r144, 2017.

42 Paul S and Lal G: The molecular mechanism of natural killer cells function and its importance in cancer immunotherapy. Front Immunol 8: 1124, 2017.
Received August 20, 2018

Revised September 26, 2018

Accepted October 2, 2018 